\title{
La força de fricció i la temperatura
}

\author{
Basili Martínez Espinet \\ IES Miquel Martí i Pol (Roda de Ter) \\ bmartine@xtec.cat
}

Es tracta d'estudiar, amb mitjans senzills, si la fricció entre dues superfícies depèn de la seva temperatura.

\section{Objectiu}

Es tracta d'un experiment senzill realitzat amb materials molt habituals i dissenyat perquè l'alumne pugui investigar la relació que hi ha entre fregament i temperatura.

\section{Material}

Fulls de cartró de $60 \times 40 \mathrm{~cm}$ aproximadament, peces de ferro de 4,7 × 2,5 x 2 (nosaltres en vàrem aprofitar unes d'uns equips vells d'Enosa), fogó elèctric, regle graduat, pinça per agafar la peça de ferro calenta i cronòmetre.

\section{Procediment experimental}

Donem a cada grup d'alumnes un full de cartró, una peça de ferro, un fogonet elèctric, una pinça i un cronòmetre. Agafem la peça i la posem sobre el cartró com es mostra a la fig. 1. Anem aixecant lentament fins que la peça comenci a lliscar i mesurem l'alçada.

Endollen tots els grups el seu fogonet a la posició de mitja potència i esperem cinc minuts perquè es posi a règim.

Agafem la peça de ferro i la posem damunt del fogó (fig. 2) durant 10 segons exactes. La retirem amb les pinces i la posem damunt del cartró, com hem fet abans.

Llavors un altre membre del grup anirà aixecant el cartró lentament fins que la peça comenci a lliscar. En aquest moment ens aturarem i mesurarem l'alçada amb la regla (fig. 3).

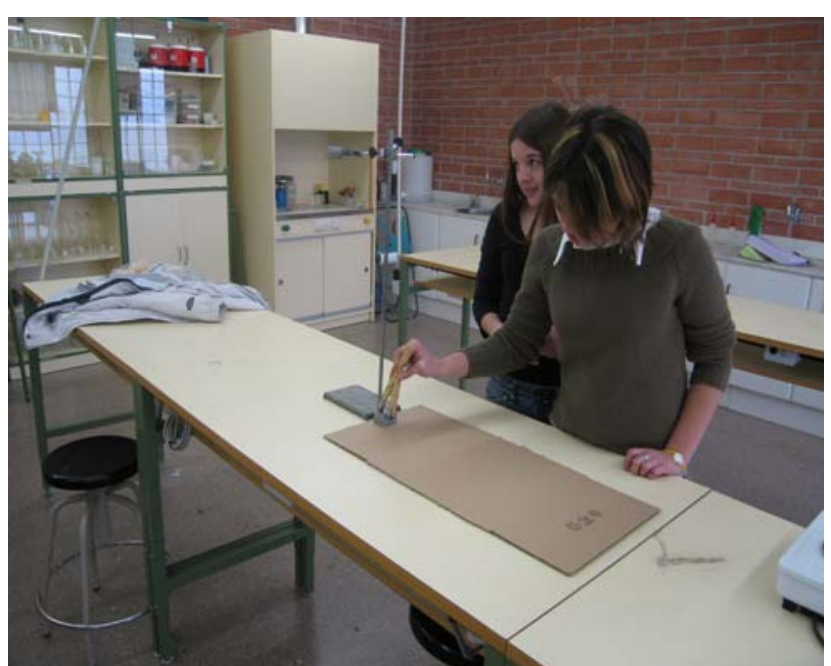

Figura 1. Col-locant la peça de ferro sobre el cartró mitjançant unes pinces.

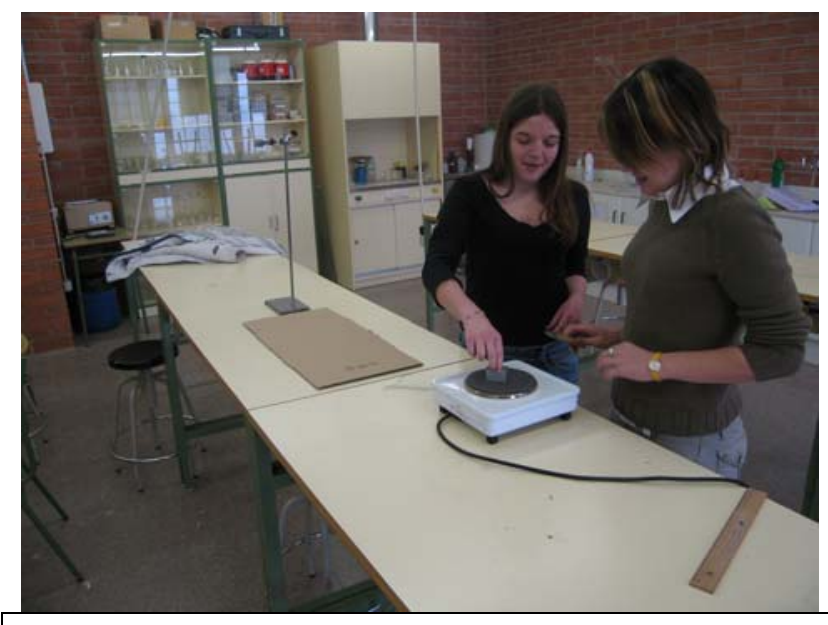

Figura 2. Escalfant la peça durant 10 segons. 


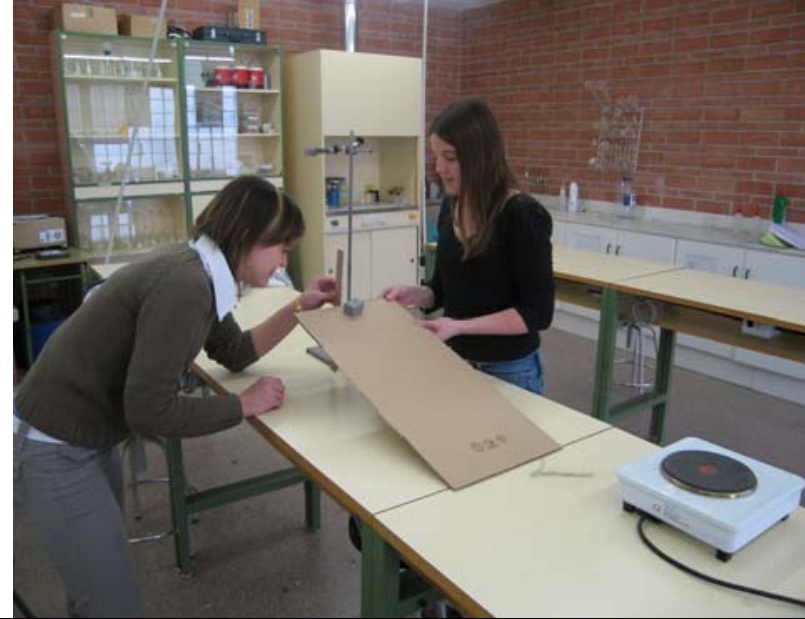

Figura 3. Quan la peça comença a lliscar es mesura amb un regle l'alçada del pla inclinat.

Ara agafarem la peça i la refredarem amb aigua de l'aixeta. L'eixugarem bé amb paper de cuina i l'escalfarem una altra vegada però ara durant 20 segons. Després repetirem el procés anterior, mesurant l'alçada un altre cop. Cada grup escalfarà també durant 30,40 i 50 segons, de manera que tindrem cinc alçades i cinc temps per cada grup.

\section{Dades}

Els alumnes hauran d'omplir dues taules: una amb els resultats del seu grup i una altra amb les mitjanes de tots els grups. (Amb cinc grups al mateix temps surt força bé).

Grup

\begin{tabular}{|l|l|l|l|l|l|l|}
\hline Temps (s) & 0 & 10 & 20 & 30 & 40 & 50 \\
\hline Alçada (cm) & & & & & & \\
\hline
\end{tabular}

Mitjana

\begin{tabular}{|l|l|l|l|l|l|l|}
\hline Temps (s) & 0 & 10 & 20 & 30 & 40 & 50 \\
\hline Alçada (cm) & & & & & & \\
\hline
\end{tabular}

\section{Representació gràfica}

En un espai aproximat de mig foli en paper quadriculat o si pot ser mil-limetrat, representem l'alçada en centímetres a l'eix vertical en funció del temps d'escalfament a l'eix horitzontal, expressat en segons. Podem representar els resultats individuals amb un color i les mitjanes amb un altre. Normalment estan més ben alineats els punts de la mitjana, que no els individuals.

\section{Conclusions}

Les dues rectes sempre solen sortir amb els punts bastant alineats i amb un pendent positiu, de manera que l'alumne pot concloure que el fregament augmenta linealment amb la temperatura en l'interval assajat.

Per orientar les conclusions podem proposar les preguntes següents:

- Com et sembla que varia el fregament amb la temperatura?

- Per què et sembla que és important fer la mitjana de tots els grups?

- Per què surten més ben alineats els punts de la mitjana que no els d'un sol grup?

- Per què cada cop que repetim l'experiment és convenient fer el mateixos passos i, si pot ser, en el mateix temps?

- Per què en les competicions de motos i cotxes escalfen els neumàtics (fig. 4) abans d'intentar fer la volta ràpida?

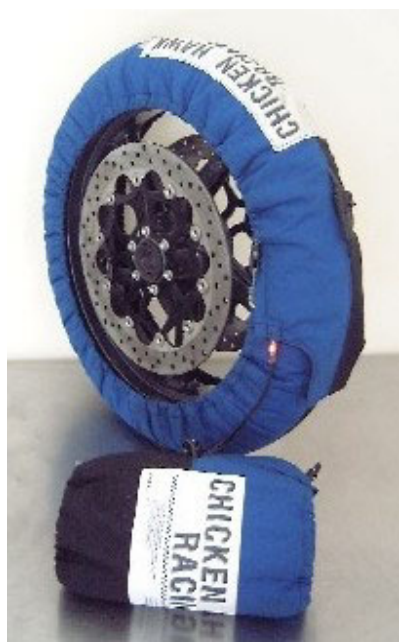

Figura 4. Escalfador de neumàtics.

\section{Comentaris}

És important remarcar que en cada repetició de l'experiment s'han de fer els mateixos passos en el mateix temps per tal de minimitzar l'error. Les temperatures de la peça de ferro poden oscil.lar normalment entre 5 i $90^{\circ} \mathrm{C}$.

Si fem aquesta pràctica amb grups de batxillerat podem calcular la desviació típica entre els resultats de diferents grups i explicar algunes coses més sobre l'error.

També podem preguntar com interpretem o com podem imaginar a nivell atòmic o molecular el fet que a l'augmentar la temperatura augmenti el fregament. 